\title{
Respective contribution of intensive care unit-acquired limb muscle and severe diaphragm weakness on weaning outcome and mortality: a post hoc analysis of two cohorts
}

\author{
Martin Dres ${ }^{1,2}$, Boris Jung ${ }^{3,4}$, Nicolas Molinari ${ }^{5}$, Federico Manna ${ }^{5}$, Bruno-Pierre Dubé ${ }^{1,2}$, Gerald Chanques ${ }^{3,6}$,
} Thomas Similowski ${ }^{1,2}$, Samir Jaber ${ }^{3,6}$ and Alexandre Demoule ${ }^{1,2,7^{*}}$ (D)

\begin{abstract}
Background: Intensive care unit (ICU)-acquired weakness (ICU-AW) and ICU-acquired diaphragm dysfunction (ICU-DD) occur frequently in mechanically ventilated (MV) patients. It is unknown whether they have different risk factors and different impacts on outcome. This study was designed to (1) describe the respective risk factors associated with ICU-AW and severe ICU-DD and (2) evaluate the respective impact of ICU-AW and severe ICU-DD on outcome.

Methods: Post hoc analysis of two prospective cohort studies conducted in two ICUs. In patients mechanically ventilated for at least $24 \mathrm{~h}$ undergoing a first spontaneous breathing trial, severe ICU-DD was defined as diaphragm twitch pressure $<7 \mathrm{cmH}_{2} \mathrm{O}$ and ICU-AW was defined as Medical Research Council Score $<48$.
\end{abstract}

Results: One hundred sixteen patients were assessed. Factors independently associated with severe ICU-DD were age, longer duration of MV, and exposure to sufentanil, and those factors associated with ICU-AW were longer duration of MV and exposure to norepinephrine. Severe ICU-DD (OR 3.56, $p=0.008)$, but not ICU-AW, was independently associated with weaning failure (59\%). ICU-AW (OR 4.30, $p=0.033$ ), but not severe ICU-DD, was associated with ICU mortality. Weaning failure and mortality rate were higher in patients with both severe ICU-DD and ICU-AW (86\% and 39\%, respectively) than in patients with either severe ICU-DD (64\% and 0\%) or ICU-AW (63\% and 13\%).

Conclusion: Severe ICU-DD and ICU-AW have different risk factors and different impacts on weaning failure and mortality. The impact of the combination of ICU-DD and ICU-AW is more pronounced than their individual impact.

Keywords: Diaphragm, Muscles, Weakness, Magnetic stimulation, Intensive care unit, Mechanical ventilation, Weaning

\section{Background}

Intensive care unit (ICU)-acquired weakness (ICU-AW) and ICU-acquired diaphragm dysfunction (ICU-DD) are two well-described complications observed in critically ill patients undergoing mechanical ventilation (MV) [1-7].

\footnotetext{
* Correspondence: alexandre.demoule@aphp.fr

${ }^{1}$ AP-HP, Sorbonne Université, Hôpital Pitié-Salpêtrière, Service de

Pneumologie, Médecine intensive - Réanimation (Département "R3S"),

F-75013 Paris, France

${ }^{2}$ AP-HP, Groupe Hospitalier Pitié-Salpêtrière Charles Foix, Intensive Care Unit and Respiratory Division (Département "R3S"), F-75013 Paris, France Full list of author information is available at the end of the article
}

ICU-AW and ICU-DD are associated with difficult and prolonged weaning and poorer outcomes $[5,8,9]$. Although ICU-AW and ICU-DD share similar characteristics, their coexistence does not seem to be strongly correlated $[5,9]$, suggesting that they may be associated with different risk factors [5].

Several studies have evaluated the interactions between respiratory and limb muscle dysfunction in critically ill patients $[5,8,9]$, but few of them have assessed diaphragm strength by twitch tracheal pressure in response to bilateral phrenic nerve stimulation (Ptr,stim),

(C) The Author(s). 2019 Open Access This article is distributed under the terms of the Creative Commons Attribution 4.0 International License (http://creativecommons.org/licenses/by/4.0/), which permits unrestricted use, distribution, and 
which is recognized to be the gold standard [5, 8-10]. In addition, these studies present a number of limitations. Firstly, they included a limited number of patients, making it difficult to evaluate the respective impact of ICU-AW and ICU-DD on outcome. Secondly, in these studies, diaphragm dysfunction was defined as Ptr,stim $<11 \mathrm{cmH}_{2} \mathrm{O}$, which is the cut-off value currently used in non-ICU patients. However, this cut-off has been recently disputed since a recent report showed that Ptr, stim $<7 \mathrm{cmH}_{2} \mathrm{O}$ would be the most reliable cut-off to predict weaning failure [10-12], as Ptr,stim $<7 \mathrm{cmH}_{2} \mathrm{O}$ defines "severe" ICU-acquired diaphragm dysfunction (S-ICU-DD), with weaning failure being the most relevant outcome [13].

We postulated that ICU-DD and ICU-AW have different risk factors with different respective impacts on outcome. To resolve this issue, we merged the population of two pre-existing cohorts [5,9] and performed a post hoc analysis. The primary objective was to describe the respective risk factors for ICU-AW and S-ICU-DD and the secondary objective was to evaluate the respective impact of ICU-AW and S-ICU-DD on outcome.

\section{Patients and methods}

Detailed methods of the two studies have been previously published $[5,9]$. The two studies were conducted in a 10-bed medical ICU in Paris, France (study 1), and in a 16-bed medical surgical ICU in Montpellier, France (study 2), and were approved by the Comité de Protection des Personnes Ile-de-France VI (Paris) and the Comité de Protection des Personnes Sud-Méditerranée (Montpellier) ethics committees. Informed consent was obtained from all patients or their relatives. Data from these cohorts have been previously published $[5,9,13,14]$.

\section{Patients}

In study 1 [5], patients intubated and ventilated for at least $24 \mathrm{~h}$ were eligible for inclusion in the study as soon as they met the predefined readiness-to-wean criteria on daily screening and were therefore deemed ready to undergo a spontaneous breathing trial (SBT). In study 2, patients were eligible for inclusion if they were diagnosed with ICU-AW (defined by a Medical Research Council $[\mathrm{MRC}]$ Score $<48$ ), had been mechanically ventilated for at least $48 \mathrm{~h}$, and were undergoing a spontaneous breathing trial.

In both studies, exclusion criteria were contraindications to magnetic stimulation of the phrenic nerves (cardiac pacemaker, implanted defibrillator, or cervical implants), pre-existing neuromuscular disorders (cervical spine injury, bihemispheric or brain stem lesions), and the impossibility to assess limb muscle strength due to immobilization or inability to follow simple instructions.

\section{Data collection}

Demographic data, comorbidities, severity scores, organ dysfunction-related variables, physiological data, blood gas data, medication exposure, duration of MV and ICU stay, and ICU and hospital mortality were prospectively recorded.

\section{Diaphragm function}

Diaphragm function was assessed in terms of changes in Ptr,stim, [3] in response to bilateral anterior magnetic stimulation of the phrenic nerves [15]. Briefly, two figure-of-eight coils connected to a pair of Magstim ${ }^{\circ} 200$ stimulators (The Magstim Company, Dyfed, UK) were positioned immediately posterior to the sternomastoid muscles at the level of the cricoid cartilage. Stimulations were delivered at the maximum intensity allowed by the stimulator. This level of power output is known to produce stimulation which is supramaximal or very close to supramaximal [15].

Patients were studied in a standardized semirecumbent position, as follows: end-expiratory pressure was set to zero, and the patient was allowed to exhale during an end-expiratory pause until expiratory airflow reached zero (relaxed equilibrium volume of the respiratory system). The endotracheal tube was then occluded and bilateral anterolateral magnetic stimulation was performed. Measurements were repeated at least three times by 2 operators to ensure reproducibility. Stimulations were always performed by the same two operators in each center. Ptr,stim was defined as the amplitude of the negative pressure wave following stimulation, measured from baseline to peak at the proximal end of the endotracheal tube, using a linear differential pressure transducer $\left(\mathrm{MP} 45 \pm 100 \mathrm{cmH}_{2} \mathrm{O}\right.$, Validyne, Northridge, CA, USA). The pressure signal was sampled and digitized at $128 \mathrm{~Hz}$ (MP30, Biopac Systems, Santa Barbara, CA, USA, or Powerlab, AD Instruments, Bella Vista, Australia) for subsequent data analysis.

\section{Limb muscle strength}

Limb muscle strength was assessed by using the Medical Research Council (MRC) score in patients screened for level of consciousness and understanding.

\section{Study design}

The spontaneous breathing trial was performed after completion of diaphragm and limb muscle assessment. Patients were connected to the ventilator (at pressure support level $7 \mathrm{cmH}_{2} \mathrm{O}$ with zero end-expiratory pressure, or by T-tube) for a 30-min period. SBT was considered to have failed when criteria of clinical intolerance were present [16]. Otherwise, the spontaneous breathing trial was considered to be successful and patients were extubated when decided by the attending physician. Successful weaning was defined as sustained spontaneous 
breathing without any form of ventilatory support $48 \mathrm{~h}$ after extubation. Weaning failure was defined as patients failing the spontaneous breathing trial or requiring reintubation or any form of ventilatory support (including noninvasive ventilation for post-extubation acute respiratory failure, but not prophylactic noninvasive ventilation) during the $48 \mathrm{~h}$ following extubation.

\section{Definitions}

Ptr,stim was used to identify two groups of patients based on the $7 \mathrm{cmH}_{2} \mathrm{O}$ cut-off already described [13], and patients with Ptr,stim $<7 \mathrm{cmH}_{2} \mathrm{O}$ were considered to have S-ICU-DD. The MRC score was used to identify two groups of patients based on the cut-off of 48/60 [1], and patients with an MRC score $<48$ were considered to have ICU-AW.

\section{Statistical analysis}

Continuous variables are expressed as median (interquartile range), and categorical variables are expressed as absolute and relative frequency. Continuous variables were compared by Kruskal-Wallis or Mann-Whitney $U$ test, and categorical variables were compared by the chisquare test or Fisher's exact test depending on the sample size. We used multiple forward logistic regression models to identify variables independently associated with ICU-AW, S-ICU-DD, weaning failure, and ICU mortality.

To identify the importance of each variable, a classification tree (CART) sequentially partitioned data into homogeneous subsamples. Starting with the complete data set, a partitioning tree searched for the best explanatory variable and the optimal cut-off value (denoted node) in order to obtain two subsamples with increasing purity for class membership. At node 1, two subsamples were obtained with a purity higher than the purity of the initial sample. Each subsample was then partitioned as before, and the best partition was selected. To ensure the robustness of the final model and to avoid potential over-fitting of the data, the model was crossvalidated to prune the tree.

For all final comparisons, a $p$ value less than or equal to 0.05 was considered to be statistically significant. Analyses were performed using SPSS, v.21 (IBM, Chicago, IL, USA) and R, v. 3.5.0.

\section{Results}

One hundred sixteen patients were enrolled during the study period: 76 in study 1 and 40 in study 2 .

\section{Prevalence and factors associated with ICU-AW and S-ICU-} DD

Figure 1 displays the distribution of patients according to the presence of ICU-AW and S-ICU-DD. Sixty-eight (59\%) patients had no S-ICU-DD, 36 (31\%) of whom had no ICU-AW and 32 (28\%) had ICU-AW. Among the remaining 48 patients with S-ICU-DD, 14 (12\%) had no ICU-AW and 34 (29\%) had ICU-AW.

Table 1 shows patient characteristics according to the presence of ICU-AW and S-ICU-DD. Compared to patients with no S-ICU-DD and no ICU-AW, patients with ICU-AW only had a higher SOFA score on ICU admission and were more frequently exposed to neuromuscular blockers and norepinephrine. Patients with S-ICU-

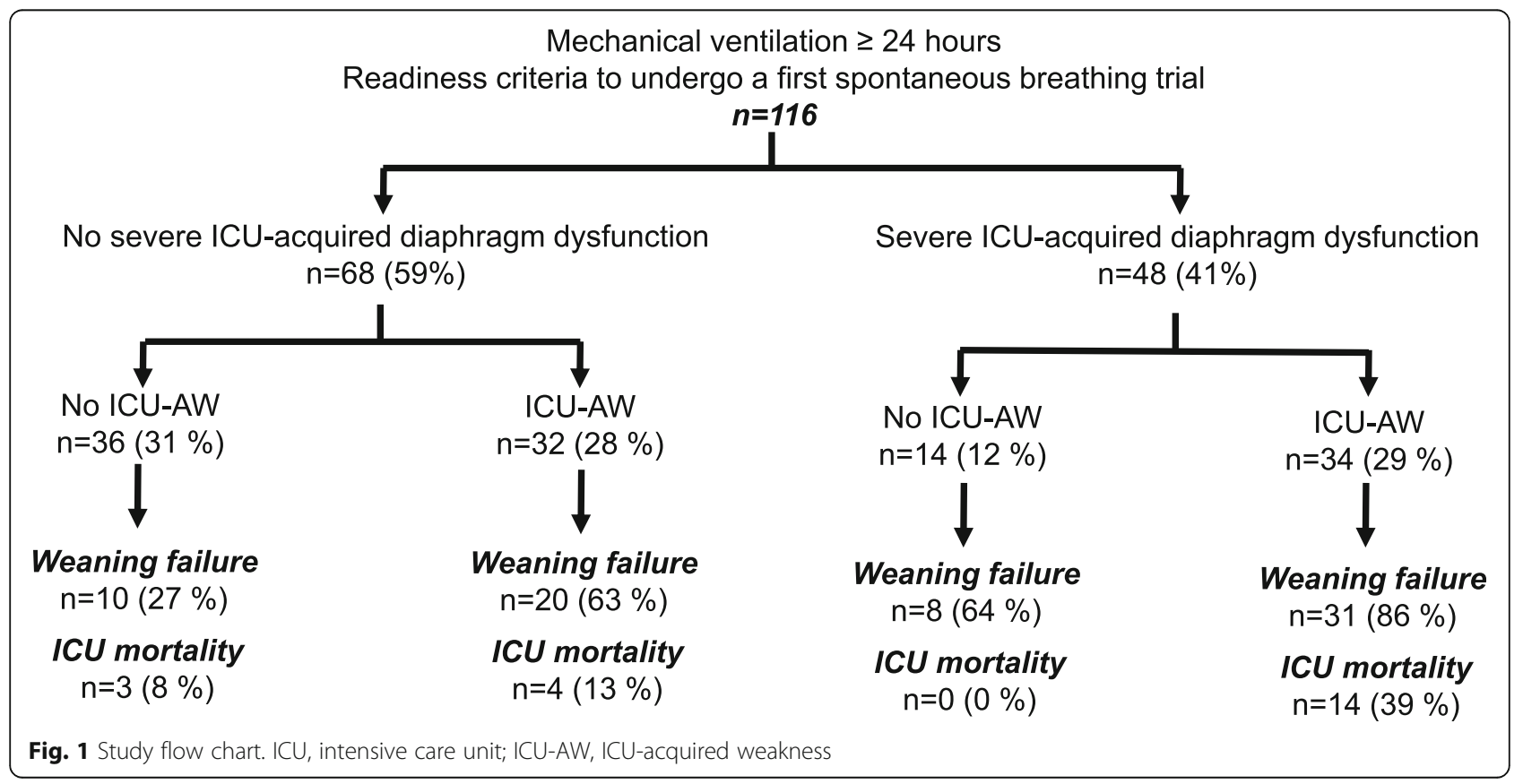


Table 1 Characteristics of the study population on intensive care unit admission according to the presence of severe intensive care unit-acquired diaphragm dysfunction (S-ICU-DD) and intensive care unit-acquired weakness (ICU-AW)

\begin{tabular}{|c|c|c|c|c|c|}
\hline \multirow[b]{3}{*}{ N } & \multicolumn{2}{|l|}{ No S-ICU-DD } & \multicolumn{2}{|l|}{ S-ICU-DD } & \multirow[t]{3}{*}{$p$} \\
\hline & No weakness & ICU-AW & No weakness & ICU-AW & \\
\hline & $36(31 \%)$ & $32(28 \%)$ & $14(12 \%)$ & $34(29 \%)$ & \\
\hline \multicolumn{6}{|l|}{ Demographic data } \\
\hline Men, $n(\%)$ & $27(75)$ & $19(59)$ & $7(58)$ & $24(71)$ & 0.522 \\
\hline Age, years & $58(40-55)$ & $56(50-65)$ & $70(50-78)^{*}$ & $64(56-75)^{* \#}$ & 0.009 \\
\hline Body mass index, $\mathrm{kg} / \mathrm{m}^{2}$ & $24(21-27)$ & $23(21-26)$ & $24(20-33)$ & $25(22-29)$ & 0.302 \\
\hline \multicolumn{6}{|l|}{ Medical conditions } \\
\hline COPD, n (\%) & $7(19)$ & $0(0)^{*}$ & $3(21)^{\#}$ & $7(21)^{\#}$ & 0.049 \\
\hline Heart failure, $n(\%)$ & $7(19)$ & $2(6)$ & $2(14)$ & $6(18)$ & 0.453 \\
\hline \multicolumn{6}{|l|}{ Reason for ICU admission } \\
\hline Shock & $11(33)$ & $10(31)$ & $3(21)$ & $13(38)$ & 0.793 \\
\hline Coma & $13(39)$ & $5(19)$ & $3(21)$ & $6(18)$ & 0.186 \\
\hline Acute respiratory failure & $12(33)$ & $17(53)$ & $8(57)$ & $15(44)$ & 0.387 \\
\hline \multicolumn{6}{|l|}{ On admission } \\
\hline SOFA & $4(3-5)$ & $7(4-10)^{*}$ & $6(5-8)^{*}$ & $8(5-13)^{*}$ & $<0.0001$ \\
\hline Sepsis, n (\%) & $24(67)$ & $23(72)$ & $7(58)$ & $23(68)$ & 0.830 \\
\hline \multicolumn{6}{|l|}{ At inclusion } \\
\hline MV prior to inclusion, days & $3(1-5)$ & $4(4-9)$ & $5(1-7)^{*}$ & $9(5-15)^{*+}$ & $<0.0001$ \\
\hline \multicolumn{6}{|l|}{ Medication exposure } \\
\hline Neuromuscular blocker, $n$ (\%) & $4(11)$ & $13(41)^{*}$ & $4(28)$ & $17(50)^{*}$ & 0.017 \\
\hline Corticosteroids, $n$ (\%) & $1(3)$ & $3(9)$ & $4(28)^{*}$ & $1(3)^{\dagger}$ & $<0.0001$ \\
\hline Norepinephrine, $n$ (\%) & $9(25)$ & $21(66)^{*}$ & $3(21)^{\#}$ & $30(88)^{*+}$ & $<0.0001$ \\
\hline Midazolam, n (\%) & $11(31)$ & $16(50)$ & $5(36)$ & $13(38)$ & 0.346 \\
\hline Propofol (\%) & $23(64)$ & $5(19)^{*}$ & $7(50)^{\#}$ & $5(15)^{* \dagger}$ & $<0.0001$ \\
\hline Sufentanil, $n$ (\%) & $16(44)$ & $21(66)$ & $7(50)$ & $31(91)^{* \dagger \#}$ & 0.001 \\
\hline \multicolumn{6}{|l|}{ Muscle assessment } \\
\hline Ptr,stim, $\mathrm{CmH}_{2} \mathrm{O}$ & $10.9(7.9-15.3)$ & $11.0(9.0-14.0)$ & $5.0(4.1-6.3)^{* \#}$ & $3.5(2.4-6.3)^{* \#}$ & $<0.0001$ \\
\hline MRC score & $56(51-59)$ & $35(23-43)^{*}$ & $55(51-57)^{\#}$ & $33(24-40)^{*^{\dagger}}$ & $<0.0001$ \\
\hline
\end{tabular}

Data are expressed as median (interquartile range) or $n(\%)$

COPD chronic obstructive pulmonary disease, SOFA Sequential Organ Failure Assessment, MV mechanical ventilation, Ptr,stim endotracheal tube pressure induced by bilateral phrenic nerve stimulation during airway occlusion, MRC Medical Research Council

*vs. No S-ICU-DD-No ICU-AW

"vs. No S-ICU-DD-ICU-AW

${ }^{\dagger}$ vs. S-ICU-DD-No ICU-AW

DD only had a higher duration of MV prior to inclusion and were more frequently exposed to corticosteroids. Compared to patients with either S-ICU-DD or ICUAW, those with both S-ICU-DD and ICU-AW had an even longer duration of MV prior to inclusion and were more frequently exposed to norepinephrine and sufentanil. Multivariate logistic regression analysis identified three factors independently associated with S-ICU-DD: age (odds ratio [OR] 1.08, 95\% confidence interval [CI] 1.04-1.13, $p=0.0001$ ), exposure to sufentanil (OR 7.38, $95 \%$ CI 2.6-23, $p=0.0003$ ), and duration of MV prior to inclusion (OR 1.09, 95\% CI 1.01-1.19, $p=0.028$ ). Two factors were independently associated with ICU-AW: exposure to norepinephrine (OR 7.2, 95\% CI 2.9-19, $p=$ 0.00003 ) and duration of MV prior to inclusion (OR $1.27,95 \%$ CI 1.13-1.47, $p=0.0003$ ).

\section{Clinical outcomes}

Table 2 shows the main clinical outcome. Compared to patients with no S-ICU-DD and no ICU-AW, patients with either S-ICU-DD or ICU-AW presented higher rates of SBT failure and weaning failure. Patients with ICU-AW but no S-ICU-DD had a longer ICU length of stay, in contrast with patients with S-ICU-DD but no ICU-AW. Compared to patients with either S-ICU-DD 
Table 2 Main clinical outcomes according to the presence of severe intensive care unit-acquired diaphragm dysfunction (S-ICU-DD) and intensive care unit-acquired weakness (ICU-AW)

\begin{tabular}{|c|c|c|c|c|c|}
\hline \multirow[b]{3}{*}{ N } & \multicolumn{2}{|l|}{ No S-ICU-DD } & \multicolumn{2}{|l|}{ S-ICU-DD } & \multirow[t]{3}{*}{ p } \\
\hline & No weakness & ICU-AW & No weakness & ICU-AW & \\
\hline & $36(31 \%)$ & $32(28 \%)$ & $14(12 \%)$ & $34(29 \%)$ & \\
\hline \multicolumn{6}{|l|}{ Outcomes } \\
\hline SBT failure, $n(\%)$ & $7(19)$ & $14(44)^{*}$ & $7(58)^{*}$ & $26(72)^{* \#}$ & $<0.0001$ \\
\hline Reintubation after extubation following successful SBT, $n$ (\%) & $3(8)$ & $6(19)^{*}$ & $1(8)$ & $8(23)^{*}$ & 0.039 \\
\hline Weaning failure, $n(\%)$ & $10(28)$ & $20(63)^{*}$ & $8(67)^{*}$ & $31(86)^{* \#}$ & $<0.0001$ \\
\hline MV until extubation, days & $4(1-6)$ & $7(4-13)^{*}$ & $7(3-8)$ & $13(7-24)^{*}$ & $<0.0001$ \\
\hline ICU length of stay, days & $5(3-14)$ & $15(7-30)^{*}$ & $9(4-13)^{\#}$ & $20(9-30)^{*^{+}}$ & $<0.000$ \\
\hline ICU mortality, n (\%) & $3(8)$ & $4(13)$ & $0(0)$ & $14(39)^{* \#+}$ & 0.001 \\
\hline
\end{tabular}

Data are expressed as median (interquartile range) or $n(\%)$

$S B T$ spontaneous breathing trial, $M V$ mechanical ventilation, $I C U$ intensive care unit

*vs. No S-ICU-DD-No ICU-AW

\#vs. No S-ICU-DD-ICU-AW

tvs. S-ICU-DD-No ICU-AW

or ICU-AW, those with both S-ICU-DD and ICU-AW had higher weaning failure and mortality rates.

The overall weaning failure rate was $59 \%$. Table 3 shows the factors associated with weaning failure identified by univariate analysis. On multivariate logistic regression analysis, two of these factors were independently associated with weaning failure: duration of MV prior to inclusion (OR 1.17, 95\% CI 1.04-1.33, $p=0.012$ ) and SICU-DD (OR 3.56, 95\% CI 1.42-9.40, $p=0.008$ ). CART analysis confirmed the impact of S-ICU-DD on weaning (Fig. 2, Panel a), as the two variables selected, S-ICU-DD and duration of MV, were most likely to identify patients who were successfully weaned from those with weaning failure.

Intensive care unit mortality rate was $18 \%$. Table 4 shows the factors associated with mortality identified by univariate analysis. On multivariate logistic regression analysis, two of these factors were independently associated with mortality: ICU-AW (OR 4.30, 95\% CI 1.2520.30, $p=0.033$ ) and age (OR 1.04, 95\%CI 1.01-1.09, $p=0.036)$. CART analysis confirmed the impact of ICUAW on mortality (Fig. 2, Panel b).

\section{Discussion}

The main results of our study are as follows: (1) some of the risk factors associated with S-ICU-DD and S-ICUAW are different; (2) S-ICU-DD, but not ICU-AW, is independently associated with weaning failure, while ICU-AW, but not S-ICU-DD, is associated with ICU mortality; and (3) the impact of the combination of SICU-DD and ICU-AW on outcome is more pronounced than the individual impact of each entity.

We observed that some of the risk factors associated with S-ICU-DD and ICU-AW were different, which is consistent with core physiological data suggesting that ICU-DD and ICU-AW may be associated with distinct
Table 3 Patient characteristics according to weaning outcome

\begin{tabular}{|c|c|c|c|}
\hline & $\begin{array}{l}\text { Weaning failure } \\
n=69(59 \%)\end{array}$ & $\begin{array}{l}\text { Weaning success } \\
n=47(41 \%)\end{array}$ & $p$ \\
\hline Men, $n(\%)$ & $44(75)$ & $33(70)$ & 0.554 \\
\hline Age, years & $60(52-71)$ & $57(67-41)$ & 0.041 \\
\hline Body mass index, $\mathrm{kg} / \mathrm{m}^{2}$ & $24(22-28)$ & $24(22-28)$ & 0.673 \\
\hline \multicolumn{4}{|l|}{ Medical conditions } \\
\hline $\begin{array}{l}\text { Chronic heart failure, } \\
n(\%)\end{array}$ & $9(13)$ & $8(17)$ & 0.607 \\
\hline COPD, $n(\%)$ & $13(19)$ & $4(9)$ & 0.188 \\
\hline \multicolumn{4}{|l|}{ Reason for ICU admission } \\
\hline Shock, $n(\%)$ & $23(32)$ & $14(30)$ & 0.845 \\
\hline Coma, $n(\%)$ & $10(17)$ & $17(36)$ & 0.032 \\
\hline $\begin{array}{l}\text { Acute respiratory } \\
\text { failure, } n(\%)\end{array}$ & $36(51)$ & $16(34)$ & 0.141 \\
\hline \multicolumn{4}{|l|}{ On admission } \\
\hline SOFA & $7(4-11)$ & $5(4-8)$ & 0.777 \\
\hline $\begin{array}{l}\text { Sepsis on admission, } \\
n(\%)\end{array}$ & $44(64)$ & $33(70)$ & 0.473 \\
\hline \multicolumn{4}{|l|}{ At inclusion } \\
\hline $\begin{array}{l}\text { MV before inclusion, } \\
\text { days }\end{array}$ & $7(4-12)$ & $3(1-5)$ & $<0.001$ \\
\hline \multicolumn{4}{|l|}{ Muscle assessment } \\
\hline $\begin{array}{l}\text { Severe ICU-DD, } \\
n(\%)\end{array}$ & $57(83)$ & $22(47)$ & $<0.001$ \\
\hline Ptr,stim, $\mathrm{CmH}_{2} \mathrm{O}$ & $6.7(3.5-8.4)$ & $11.3(7.7-15.8)$ & $<0.001$ \\
\hline ICU-AW, n (\%) & $49(71)$ & $17(36)$ & $<0.001$ \\
\hline MRC score & $36(30-50)$ & $52(44-58)$ & 0.014 \\
\hline
\end{tabular}

Data are expressed as median (interquartile range) or $n(\%)$

COPD chronic obstructive pulmonary disease, SOFA Sequential Organ Failure Assessment, MV mechanical ventilation, Ptr,stim endotracheal tube pressure induced by bilateral phrenic nerve stimulation during airway occlusion, S-ICU$D D$ severe intensive care unit-acquired diaphragm dysfunction, ICU-AW intensive care unit-acquired weakness, MRC Medical Research Council 


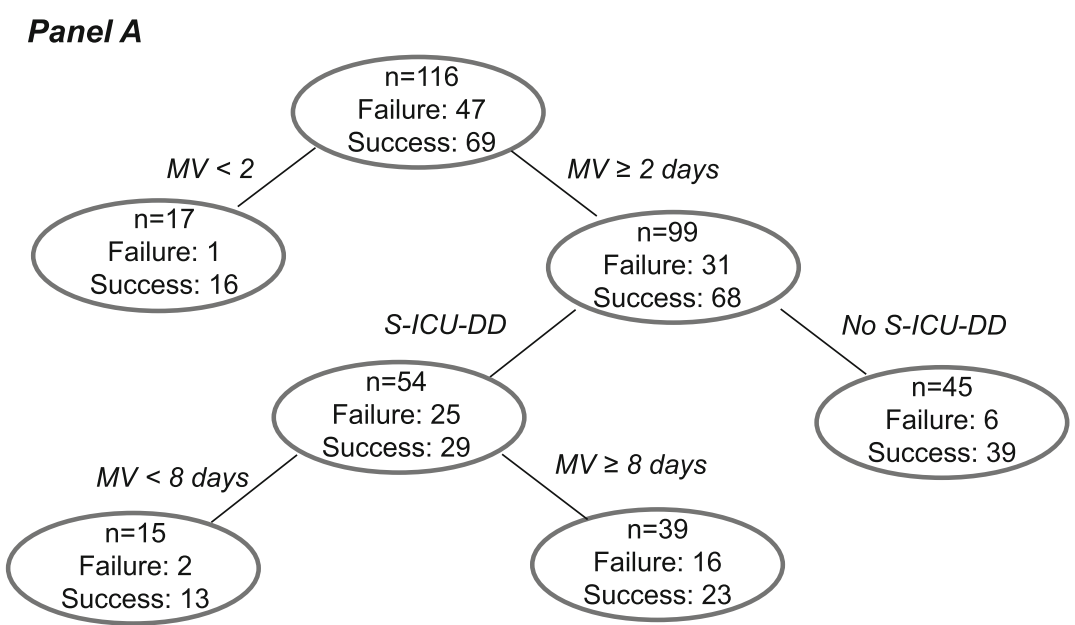

Panel B

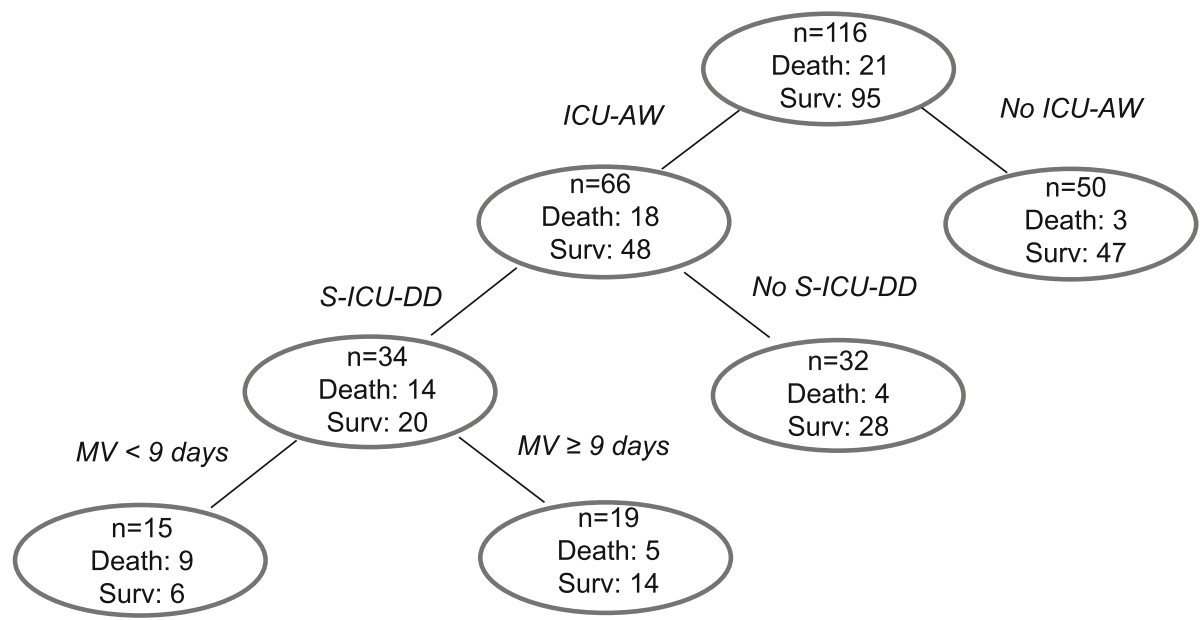

Fig. 2 Nonparametric classification and regression tree methodology (CART) selected variables as decision knots, ensuring optimal separation of patients successfully weaned from mechanical ventilation from those not successfully weaned (a) and optimal separation of survivors from non-survivors (b). MV, duration of mechanical ventilation prior to inclusion; S-ICU-DD, severe intensive care unit-acquired diaphragm dysfunction; ICU-AW, intensive care unit-acquired weakness

risk factors [17-21]. Here, exposure to sufentanil was associated with S-ICU-DD but not ICU-AW, which reminds us that the use of opioids should be limited in quantity in ICU patients [22]. Clearly, diaphragm and limb muscles are different, and they are not equally vulnerable to a given injury. This is for instance the case of pneumonia, sepsis, or $\mathrm{MV}$, to which the diaphragm is more vulnerable $[1,18,23-28]$. Conversely, limb muscles are more vulnerable to hemorrhagic shock [29]. This unequal vulnerability might be explained by differences in terms of activity [30], microcirculation [29], cytokines [23], chemokines [23], and free radicals involved in oxidative stress [31]. However, the purely observational design of this study precludes any conclusions regarding why and how a given factor associated with ICU-acquired muscle weakness more specifically targets the diaphragm or limb muscles. Further studies are clearly needed. It is noteworthy that, although the two entities appeared to be partially independent, a substantial number of patients presented both S-ICU-DD and ICU-AW. These patients presented a combination of risk factors associated with S-ICU-DD and risk factors associated with ICU-AW.

In the present study, as previously observed, ICU-AW and S-ICU-DD each had an individual impact on outcome $[1,5,8]$. However, we showed that these two entities had a different individual impact on outcome, as S-ICU-DD but not ICU-AW was independently associated with weaning failure, and ICU-AW but not S-ICU-DD was associated with ICU mortality. This finding highlights the fact that diaphragm and limb muscles may have different roles in critically ill patients. The diaphragm is the main 
Table 4 Patient characteristics according to outcome

\begin{tabular}{|c|c|c|c|}
\hline & Survivors $n=95(82 \%)$ & Non-survivors $n=21$ (18\%) & $p$ \\
\hline Men, $n(\%)$ & $62(65)$ & $15(71)$ & 0.588 \\
\hline Age, years & $57(48-67)$ & $65(56-75)$ & 0.035 \\
\hline Body mass index, $\mathrm{kg} / \mathrm{m}^{2}$ & $24(21-28)$ & $25(22-29)$ & 0.282 \\
\hline \multicolumn{4}{|l|}{ Medical conditions } \\
\hline Chronic heart failure, $n$ (\%) & $13(14)$ & $4(19)$ & 0.529 \\
\hline COPD, $n(\%)$ & $13(14)$ & $4(19)$ & 0.529 \\
\hline \multicolumn{4}{|l|}{ Reason for ICU admission } \\
\hline Shock, $n(\%)$ & $29(32)$ & $8(33)$ & 0.876 \\
\hline Coma, $n(\%)$ & $25(28)$ & $2(14)$ & 0.181 \\
\hline Acute respiratory failure, $n$ (\%) & $41(43)$ & $11(52)$ & 0.442 \\
\hline \multicolumn{4}{|l|}{ On admission } \\
\hline SOFA & $5(4-9)$ & $8(4-15)$ & 0.100 \\
\hline Sepsis admission & $61(64)$ & $16(76)$ & 0.293 \\
\hline \multicolumn{4}{|l|}{ At inclusion } \\
\hline MV before inclusion, days & $5(2-9)$ & $7(5-12)$ & 0.056 \\
\hline \multicolumn{4}{|l|}{ Muscle assessment } \\
\hline S-ICU-DD, $n$ (\%) & $34(36)$ & $14(67)$ & 0.009 \\
\hline Ptr,stim, $\mathrm{CmH}_{2} \mathrm{O}$ & $8.4(5.7-13.0)$ & $4.1(2.8-8.4)$ & 0.001 \\
\hline ICU-AW, n (\%) & $48(50)$ & $18(86)$ & 0.005 \\
\hline MRC score & $47(35-55)$ & $32(19-51)$ & $<0.0001$ \\
\hline
\end{tabular}

Data are expressed as median (interquartile range) or $n(\%)$

COPD chronic obstructive pulmonary disease, SOFA Sequential Organ Failure Assessment, MV mechanical ventilation, Ptr,stim endotracheal tube pressure induced by bilateral phrenic nerve stimulation during airway occlusion, S-ICU-DD severe intensive care unit-acquired diaphragm dysfunction, ICU-AW intensive care unitacquired weakness, MRC Medical Research Council

inspiratory muscle, which is why the diaphragm pump is essential for spontaneous breathing, at least in the ICU where most patients experience increased respiratory loading. Patients with severe diaphragm dysfunction are subsequently at high risk of spontaneous breathing trial failure $[5,13]$. A recent study showed that diaphragm dysfunction is associated with prolonged weaning [32]. Following extubation, patients with severe diaphragm dysfunction may also be unable to sustain spontaneous breathing [33]. Low tidal volume due to diaphragm dysfunction is likely to cause atelectasis [34], and these patients are at high risk of immediate post-extubation acute respiratory failure [5].

With a few exceptions, weaning from $M V$ is a mandatory, but not sufficient, condition to remain alive. However, extubated patients must also be able to drain and evacuate even copious secretions, which is why adequate cough and the ability to swallow are important extubation criteria. Weak cough is definitely a major cause of delayed post-extubation acute respiratory failure [35] that may ultimately increase mortality [36]. In addition, ICU-AW induces bed rest, which, in turn, promotes atelectasis, hospital-acquired infections including pneumonia, thrombophlebitis, and skin damage [37, 38].
ICU-AW is associated with weak cough, which may explain why ICU-AW is independently associated with mortality, while S-ICU-DD is not. In addition, we observed that patients with both S-ICU-DD and ICU-AW had a poorer outcome than patients with either ICU-AW or S-ICU-DD. To the best of our knowledge, this study shows for the first time that S-ICU-DD and ICU-AW have a cumulative impact on outcome.

The strengths of our study include the largest cohort of critically ill patients in whom diaphragm function and limb muscle strength have been evaluated, the fact that our cohort included patients from two centers and the use of Ptr,stim to study diaphragm function. In addition, we focused on severe ICU-DD rather than ICU-DD because severe ICU-DD is more reliable to predict weaning failure than ICU-DD [13].

Our study presents several limitations. Firstly, the use of phrenic nerve stimulation as the reference technique to define diaphragm dysfunction excluded some eligible patients in whom this technique was contraindicated [39]. Secondly, ICU-AW was diagnosed by means of the MRC score after ruling out causes of limb weakness other than critical illness. Although the accuracy of the MRC score has been questioned [40], it is reproducible 
[41] and performed routinely in the two participating ICUs. Dynamometry or measurement of adductor pollicis muscle function by magnetic stimulation of the ulnar nerve [42] is not as reproducible as MRC score and is much more time-consuming. Thirdly, the patients were eligible for inclusion if they were intubated and ventilated for at least $24 \mathrm{~h}$ in study 1 and $48 \mathrm{~h}$ in study 2 . Although it may create a selection bias, we feel that it is not major. In addition, it creates a little more heterogeneous population, which is closer to what is encountered in daily practice.

\section{Conclusion}

In conclusion, in a prospective cohort of 116 critically ill MV patients, the risk factors associated with ICU-AW and S-ICU-DD were different, highlighting the fact that these two entities may be due to distinct mechanisms. These mechanisms and the reason why they differ between the diaphragm and limb muscles need to be more clearly elucidated. S-ICU-DD and ICU-AW also have different impacts on mortality, as ICU-DD is independently associated with weaning failure and ICU-AW is independently associated with mortality. In addition, the impact of the combination of ICU-DD and ICU-AW on outcome is more pronounced than their individual impact. These results highlight the fact that ICU-DD and ICU-AW should be evaluated separately in critically ill MV patients.

\section{Abbreviations}

ICU: Intensive care unit; ICU-AW: Intensive care unit-acquired weakness; SICU-DD: Severe intensive care unit-acquired diaphragm dysfunction; MV: Mechanical ventilation; CART: Classification and regression tree; SBT: Spontaneous breathing trial; MRC: Medical Research Council

\section{Acknowledgements}

Not applicable.

\section{Authors' contributions}

$A D, M D, S J$, and TS designed the study. AD, MD, SJ, and TS coordinated the study. AD, MD, BPD, BJ, and GC were responsible for patient screening, enrollment, diaphragm assessment, and follow-up. NM and FM performed the statistical analysis. AD, MD, SJ, TS, NM, and FM analyzed the data and wrote the manuscript. All authors contributed to interpretation of the data and provided comments on the report at various stages of development. All authors read and approved the final manuscript.

\section{Funding}

Supported by the French Ministry of Health 2005 Programme Hospitalier de Recherche Clinique (PHRC), the French Intensive Care Society (SRLF bourse de mobilité 2015), the 2015 Short Term Fellowship program of the European Respiratory Society, the 2015 Bernhard Dräger Award for advanced treatment of ARF of the European Society of Intensive Care Medicine, the Fondation pour la Recherche Médicale (FDM 20150734498), and by Mitacs Globalink Sorbonne Universités. The clinical research of "Département R3S" is supported by the program "investissement d'avenir ANR-10-AlHU 06" of the French Government.

\section{Availability of data and materials}

The datasets used and/or analyzed during the current study are available from the corresponding author on reasonable request.

\section{Ethics approval and consent to participate}

Human Research Ethics Committee approval for study 1 was given by the Comité de Protection des Personnes Ile-de-France $\boldsymbol{V}$ (Paris) and for study 2 by the Comité de Protection des Personnes Sud-Méditerranée (Montpellier).

Patients or next of kin gave informed consent.

\section{Consent for publication}

Not applicable.

\section{Competing interests}

Martin Dres reports personal fees from Lungpacer, outside the submitted work. Boris Jung declares no competing interests. Nicolas Molinari declares no competing interests. Federico Manna declares no competing interests. Gerald Chanques reports personal fees from Aspen medical and personal fees from Orion pharma, during the conduct of the study. Samir Jaber declares no competing interests. Thomas Similowski reports receiving personal fees from Almirall France, personal fees from AstraZeneca France, corporate personal fees from Boehringer Ingelheim France, personal fees from GlaxoSmithKline France, personal fees from Invacare, personal fees from Mundipharma, personal fees and nonfinancial support from Novartis France, personal fees from Pfizer France, grants and personal fees from Pierre Fabre Médicaments, personal fees from Takeda, personal fees from Teva Pharma, and personal fees from Lungpacer Medical Inc., all outside the submitted work. Alexandre Demoule reports personal fees from Medtronic; grants, personal fees, and non-financial support from Philips; personal fees from Baxter; personal fees from Hamilton; personal fees and non-financial support from Fisher \& Paykel; grants from French Ministry of Health; personal fees from Getinge; grants and personal fees from Respinor; and grants and nonfinancial support from Lungpacer. Brunop-Pierre Dubé received personal fees from Grifols, Boehringer Ingelheim and Roche, and has signed clinical research contracts with Sanofi, Roche and Boehringer Ingelheim.

\section{Author details}

${ }^{1}$ AP-HP, Sorbonne Université, Hôpital Pitié-Salpêtrière, Service de Pneumologie, Médecine intensive - Réanimation (Département "R3S"), F-75013 Paris, France. ${ }^{2}$ AP-HP, Groupe Hospitalier Pitié-Salpêtrière Charles Foix, Intensive Care Unit and Respiratory Division (Département "R3S"), F-75013 Paris, France. ${ }^{3}$ Montpellier School of Medicine, University of Montpellier, INSERM U1046, CNRS UMR 9214, Montpellier, France. ${ }^{4}$ Medical Intensive Care Unit, Lapeyronie University Hospital, Montpellier, France. ${ }^{5}$ Department of Statistics, CHU Montpellier, IMAG, CNRS, Univ Montpellier, Montpellier, France. ${ }^{6}$ Intensive Care and Anesthesiology Department, Saint Eloi Hospital, Montpellier, France. ${ }^{7}$ Service de Pneumologie, Médecine Intensive et Réanimation, Groupe Hospitalier Pitié-Salpêtrière, 47-83 Boulevard de l'Hôpital, 75651 Paris Cedex 13, France.

Received: 4 August 2019 Accepted: 16 October 2019

Published online: 21 November 2019

\section{References}

1. De Jonghe B, Sharshar T, Lefaucheur J-P, Authier F-J, Durand-Zaleski I, Boussarsar $\mathrm{M}$, et al. Paresis acquired in the intensive care unit: a prospective multicenter study. JAMA. 2002;288:2859-67.

2. Fan E, Cheek F, Chlan L, Gosselink R, Hart N, Herridge MS, et al. An official American Thoracic Society Clinical Practice guideline: the diagnosis of intensive care unit-acquired weakness in adults. Am J Respir Crit Care Med. 2014;190:1437-46

3. Demoule A, Jung B, Prodanovic H, Molinari N, Chanques G, Coirault C, et al. Diaphragm dysfunction on admission to the intensive care unit. Prevalence, risk factors, and prognostic impact-a prospective study. Am J Respir Crit Care Med. 2013;188:213-9.

4. Jaber S, Petrof BJ, Jung B, Chanques G, Berthet J-P, Rabuel C, et al. Rapidly progressive diaphragmatic weakness and injury during mechanical ventilation in humans. Am J Respir Crit Care Med. 2011;183:364-71.

5. Dres M, Dubé B-P, Mayaux J, Delemazure J, Reuter D, Brochard L, et al. Coexistence and impact of limb muscle and diaphragm weakness at time of liberation from mechanical ventilation in medical intensive care unit patients. Am J Respir Crit Care Med. 2017;195:57-66.

6. Goligher EC, Dres M, Fan E, Rubenfeld GD, Scales DC, Herridge MS, et al. Mechanical ventilation-induced diaphragm atrophy strongly impacts clinical outcomes. Am J Respir Crit Care Med. 2018;197:204-13. 
7. Goligher EC, Fan E, Herridge MS, Murray A, Vorona S, Brace D, et al. Evolution of diaphragm thickness during mechanical ventilation. Impact of inspiratory effort. Am J Respir Crit Care Med. 2015;192:1080-8.

8. De Jonghe B, Bastuji-Garin S, Durand M-C, Malissin I, Rodrigues P, Cerf C, et al. Respiratory weakness is associated with limb weakness and delayed weaning in critical illness. Crit Care Med. 2007:35:2007-15.

9. Jung B, Moury PH, Mahul M, de Jong A, Galia F, Prades A, et al. Diaphragmatic dysfunction in patients with ICU-acquired weakness and its impact on extubation failure. Intensive Care Med. 2016;42:853-61.

10. Qing $Q$, Liang $M$, Sun $Q$, Xie B, Yang C, Liang W, et al. Using twitch tracheal airway pressure, negative inhale forced pressure, and Medical Research Council score to guide weaning from mechanical ventilation. J Thorac Dis. 2018;10:4424-32.

11. Hamnegård CH, Wragg SD, Mills GH, Kyroussis D, Polkey Ml, Bake B, et al. Clinical assessment of diaphragm strength by cervical magnetic stimulation of the phrenic nerves. Thorax. 1996;51:1239-42.

12. Laveneziana P, Albuquerque A, Aliverti A, Babb T, Barreiro E, Dres M, et al. ERS statement on respiratory muscle testing at rest and during exercise. Eur Respir J. 2019;53:1801214.

13. Dres M, Goligher EC, Dubé B-P, Morawiec E, Dangers L, Reuter D, et al. Diaphragm function and weaning from mechanical ventilation: an ultrasound and phrenic nerve stimulation clinical study. Ann Intensive Care. 2018;8:53.

14. Dubé B-P, Dres M, Mayaux J, Demiri S, Similowski T, Demoule A. Ultrasound evaluation of diaphragm function in mechanically ventilated patients: comparison to phrenic stimulation and prognostic implications. Thorax. 2017;72:811-8.

15. Mills $\mathrm{GH}$, Kyroussis D, Hamnegard CH, Polkey Ml, Green M, Moxham J. Bilateral magnetic stimulation of the phrenic nerves from an anterolateral approach. Am J Respir Crit Care Med. 1996;154:1099-105.

16. Boles J-M, Bion J, Connors A, Herridge M, Marsh B, Melot C, et al. Weaning from mechanical ventilation. Eur Respir J. 2007;29:1033-56.

17. Berger D, Bloechlinger S, von Haehling S, Doehner W, Takala J, Z'Graggen WJ, et al. Dysfunction of respiratory muscles in critically ill patients on the intensive care unit. J Cachexia Sarcopenia Muscle. 2016;7:403-12.

18. Levine S, Nguyen T, Taylor N, Friscia ME, Budak MT, Rothenberg P, et al. Rapid disuse atrophy of diaphragm fibers in mechanically ventilated humans. N Engl J Med. 2008;358:1327-35.

19. Mrozek S, Jung B, Petrof BJ, Pauly M, Roberge S, Lacampagne A, et al. Rapid onset of specific diaphragm weakness in a healthy murine model of ventilatorinduced diaphragmatic dysfunction. Anesthesiology. 2012;117:560-7.

20. Polla B. Respiratory muscle fibres: specialisation and plasticity. Thorax. 2004; 59:808-17.

21. Welvaart WN, Paul MA, Stienen GJM, van Hees HWH, Loer SA, Bouwman RA, et al. Selective diaphragm muscle weakness after contractile inactivity during thoracic surgery. Ann Surg. 2011;254:1044-9.

22. Devlin JW, Skrobik Y, Gélinas C, Needham DM, Slooter AJC, Pandharipande $\mathrm{PP}$, et al. Clinical practice guidelines for the prevention and management of pain, agitation/sedation, delirium, immobility, and sleep disruption in adult patients in the ICU. Crit Care Med. 2018;46:e825-73.

23. Demoule A, Divangahi M, Yahiaoui L, Danialou G, Gvozdic D, Labbe K, et al. Endotoxin triggers nuclear factor-kappaB-dependent up-regulation of multiple proinflammatory genes in the diaphragm. Am J Respir Crit Care Med. 2006;174:646-53.

24. Dres M, Demoule A. Diaphragm dysfunction during weaning from mechanical ventilation: an underestimated phenomenon with clinical implications. Crit Care. 2018:22:73.

25. Divangahi M, Matecki S, Dudley RWR, Tuck SA, Bao W, Radzioch D, et al. Preferential diaphragmatic weakness during sustained Pseudomonas aeruginosa lung infection. Am J Respir Crit Care Med. 2004;169:679-86.

26. Ali NA, O'Brien JM, Hoffmann SP, Phillips G, Garland A, Finley JCW, et al. Acquired weakness, handgrip strength, and mortality in critically ill patients. Am J Respir Crit Care Med. 2008;178:261-8.

27. Sharshar T, Bastuji-Garin S, Stevens RD, Durand M-C, Malissin I, Rodriguez P, et al. Presence and severity of intensive care unit-acquired paresis at time of awakening are associated with increased intensive care unit and hospital mortality. Crit Care Med. 2009;37:3047-53.

28. Vivier E, Roussey A, Doroszewski F, Rosselli S, Pommier C, Carteaux G, et al. Atrophy of diaphragm and pectoral muscles in critically ill patients. Anesthesiology. 2019;131:569-79.

29. Carreira S, Lê Dinh M, Soubeyrand M, Poloujadoff M-P, Riou B, Similowski T, et al. Diaphragmatic function is preserved during severe hemorrhagic shock in the rat. Anesthesiology. 2014;120:425-35.
30. Ebihara S, Hussain SNA, Danialou G, Cho W-K, Gottfried SB, Petrof BJ. Mechanical ventilation protects against diaphragm injury in sepsis: interaction of oxidative and mechanical stresses. Am J Respir Crit Care Med. 2002:165:221-8.

31. Lin MC, Ebihara S, El Dwairi Q, Hussain SN, Yang L, Gottfried SB, et al. Diaphragm sarcolemmal injury is induced by sepsis and alleviated by nitric oxide synthase inhibition. Am J Respir Crit Care Med. 1998;158:1656-63.

32. Demoule A, Molinari N, Jung B, Prodanovic H, Chanques G, Matecki S, et al. Patterns of diaphragm function in critically ill patients receiving prolonged mechanical ventilation: a prospective longitudinal study. Ann Intensive Care. 2016;6:75.

33. Vivier E, Muller M, Putegnat J-B, Steyer J, Barrau S, Boissier F, et al. Inability of diaphragm ultrasound to predict extubation failure: a multicenter study. Chest. 2019;155:1131-9.

34. Wilcox P, Baile EM, Hards J, Müller NL, Dunn L, Pardy RL, et al. Phrenic nerve function and its relationship to atelectasis after coronary artery bypass surgery. Chest. 1988;93:693-8.

35. Thille AW, Boissier F, Ben Ghezala H, Razazi K, Mekontso-Dessap A, BrunBuisson C. Risk factors for and prediction by caregivers of extubation failure in ICU patients: a prospective study. Crit Care Med. 2015;43:613-20.

36. Thille AW, Cortés-Puch I, Esteban A. Weaning from the ventilator and extubation in ICU. Curr Opin Crit Care. 2013:19:57-64.

37. Allen C, Glasziou P, Del Mar C. Bed rest: a potentially harmful treatment needing more careful evaluation. Lancet. 1999:354:1229-33.

38. Asher RA. The dangers of going to bed. Crit Care Update. 1983;10:40-1 51.

39. Laveneziana P et al. ERS Statement on Respiratory Muscle Testing at Rest and during Exercise. - PubMed - NCBI [Internet]. [cited 2019 Apr 24]. Available from: https://www.ncbi.nlm.nih.gov/pubmed/?term=dres+ laveneziana.

40. Connolly BA, Jones GD, Curtis AA, Murphy PB, Douiri A, Hopkinson NS, et al. Clinical predictive value of manual muscle strength testing during critical illness: an observational cohort study. Crit Care. 2013;17:R229.

41. Hermans G, Clerckx B, Vanhullebusch T, Segers J, Vanpee G, Robbeets C, et al. Interobserver agreement of Medical Research Council sum-score and handgrip strength in the intensive care unit. Muscle Nerve. 2012:45:18-25.

42. Harris ML, Luo YM, Watson AC, Rafferty GF, Polkey Ml, Green M, et al. Adductor pollicis twitch tension assessed by magnetic stimulation of the ulnar nerve. Am J Respir Crit Care Med. 2000;162:240-5.

\section{Publisher's Note}

Springer Nature remains neutral with regard to jurisdictional claims in published maps and institutional affiliations.
Ready to submit your research? Choose BMC and benefit from:

- fast, convenient online submission

- thorough peer review by experienced researchers in your field

- rapid publication on acceptance

- support for research data, including large and complex data types

- gold Open Access which fosters wider collaboration and increased citations

- maximum visibility for your research: over $100 \mathrm{M}$ website views per year

At $\mathrm{BMC}$, research is always in progress.

Learn more biomedcentral.com/submissions 